This information is current as of April 26, 2023.

\title{
Time to Discontinue Use of the Term Stroke in Neuroradiology
}

D.A.L. Ortega, A.J. Morillo and S. González-Gómez

AJNR Am J Neuroradiol 2020, 41 (5) E33

doi: https://doi.org/10.3174/ajnr.A6479

http://www.ajnr.org/content/41/5/E33 


\section{Time to Discontinue Use of the Term Stroke in Neuroradiology}

W e read with interest the editorial of Aftab and Salman ${ }^{1}$ about discontinuing the use of the term "hemorrhagic stroke." The word "stroke" was coined in medicine to define an acute focal deficit event of the central nervous system of vascular origin $^{2}$ and has been very useful in clinical practice. The division into ischemic and hemorrhagic has served to make a rapid classification of acute cerebrovascular events.

The term "stroke" is unique in the medical literature in English and is not used in other languages. Older words such as "apoplexy" that have their equivalent in other languages have long since ceased to be used, and it is preferred to use "cerebrovascular attack," "event," or "accident." With the advances in the images of the central nervous system and with the globalization of medical knowledge, it is no longer justified to use the term "stroke" in neuroradiology to define lesions of vascular origin. Terms such as "infarct," "hypoperfusion," or "focal ischemia" are more precise and better explain the pathophysiology of the neurologic deficit.

Finally, the editorial says that ischemic events are caused by hypoperfusion of a region of the brain secondary to vascular occlusion or hypoxia. It seems controversial to say that hypoxia causes cerebral hypoperfusion; usually, the opposite is true. ${ }^{3}$

\section{REFERENCES}

1. Aftab M, Salman M. Time to discontinue use of the term "hemorrhagic stroke." AJNR Am J Neuroradiol 2019;40:1893 CrossRef Medline

2. Sacco RL, Kasner SE, Broderick JP, et al; Council on Nutrition, Physical Activity and Metabolism. An updated definition of stroke for the 21st century: a statement for healthcare professionals from the American Heart Association/American Stroke Association. Stroke 2013;44:2064-89 CrossRef Medline

3. Xing C, Arai K, Lo EH, et al. Pathophysiologic cascades in ischemic stroke. Int J Stroke 2012;7:378-85 CrossRef Medline

(1) D.A.L. Ortega Fundación Santa Fé de Bogotá Universidad El Bosque Bogotá, Colombia

(D)A.J. Morillo Fundación Santa Fé de Bogotá Bogotá, Colombia

(1)S. González-Gómez Fundación Santa Fé de Bogotá Universidad El Bosque Bogotá, Colombia 